\title{
Impact of Garbage on Climate
}

\section{Khalidullin $\mathbf{O H}^{*}$}

Kazakh National University, Kazakhstan

*Corresponding Author: Khalidullin OH, Kazakh National University, Kazakhstan.
Received: April 09, 2021

Published: May 07, 2021

(C) All rights are reserved by Khalidullin $\mathbf{0 H}$
Based on the article CLIMATE AND SKI (https://actascientific. com/ASMI/pdf/ASMI-04-0806.pdf).

Only the outer wall is taken from the idea of the tower of Babel. In essence, we offer garbage collection on very large heaps. The existing pressing with stacking layers on top of each other gives a maximum storage height of no more than 70 meters. The new method will make it possible to create mountains up to a kilometer or more. Even if the base is a radius of 2 - 3 kilometers. Of course, calculations and experiment are needed. A giant sealed container is created with a large volume of debris. The new facility harmoniously fits into the active circulation of substances and does not destroy the environment. Inside there are controlled processes of converting waste into useful substances. Outside, there is an active infrastructure - greenhouses and growing plants in summer. In winter - ski slopes for skiing.

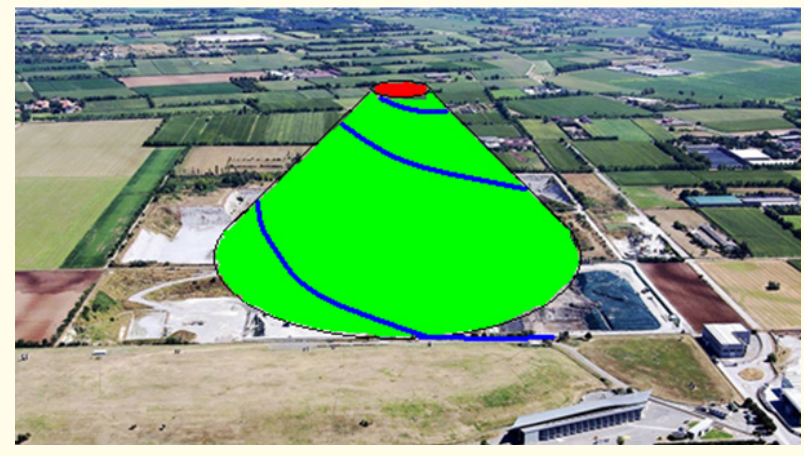

Figure 1

The spiral width, pitch and wall height are determined depending on the fluidity of the debris. With increasing pressure from above, it is possible to increase the force vector to the sides - on the walls. The strength of the fence also depends on this.

The vertical fence is made of durable plastic sheet. Options for using a concrete wall or cable-stayed structures can be considered.
Possible capital metal frames from pipes with liquids and gases.

The real idea emerged from the analysis of the problems of urban waste disposal. Developed countries were able to organize separate collection and use of different types of waste and incineration. Other countries are trying to follow the same path, but not all succeed.

To implement such methods, large investments are required in the creation and equipment of sorting and processing enterprises. It is a parasitic industry that distracts and loads a lot of labor, material and financial resources. And the restructuring of the consciousness of all citizens of these countries does not come immediately. Every citizen is obliged to strictly sort his garbage into glass, plastic, paper, food waste. And pay fines for non-performance. Therefore, garbage will not be sorted soon in such countries, and it still goes to the growing landfills, destroying the organic matter of new territories and contaminating the atmosphere and soil with gases and liquid chemicals - affecting the climate.

Garbage, completely sealed, becomes a new living entity in nature. It has its own life support with its own systems of respiration, water consumption, heat balance, chemical and biological processes. Many different components of garbage at different combinations, pressures and temperatures synthesize a variety of chemical elements - gases, liquids, heat. All processes are controlled by automation, the emissions are selected and used in production as raw materials for new products. A harmful effect on nature is excluded. But this is in the near future, as the study and development of a new direction.

The heat of decay and methane are now clearly visible, which can be captured and used. The third element is compost. If only these three elements are removed, then the initial construction costs can already be recovered. A closer study will give other opportunities for obtaining useful and necessary products.

It turns out that the landfill can be used as a source of useful nutrients. 
This requires a sufficiently good isolation of the collected debris. The shown "tower of Babel" is such a vessel. What remains is the creation of systems of pipes, drainage, ventilation, pipes with sensors of measurement, control and management systems.

Structurally, the alignment of pipes with wall supports can have a significant effect on creating the strength of the overall structure.

It is assumed that as rotting or composting, the volume of the garbage should decrease. To preserve the walls and external infrastructure and the process of obtaining heat and chemical elements, supplement with new debris and soil. For this, it will be necessary to monitor and control the density of materials and pressure. It will be possible to supplement through the sealed hatches prepared during construction. All of these water, gas and cable pipes are installed with a dual purpose. They can be wall supports. Air supply and gas removal systems, water supply systems, pipes are designed in such a way that they evenly penetrate the entire volume of debris in order to ensure a normal decomposition process. It may be more rational to lay on the terrace, also in a spiral under the coating layer.

The elements of sealing, strengthening the capacity, and the separation of composting products must be constantly monitored, studied, and improved.

It is interesting to create housing inside this entire array. In essence, the building industry has been producing and building houses for thousands of years from materials that need to be compact. The need is caused by the desire to locate many apartments in a small area. The disadvantage of this type of construction is the conduction of heat and noise through walls and ceilings. When placing premises inside the garbage, the thickness of the walls is not limited diminishes. The multi-meter thickness of the sealed walls will provide warmth and silence.

If the idea is implemented, then all that remains is the separation of harmful and radioactive substances from the garbage, such as used batteries, oils. Each family can separate all such substances at home, and send the rest to the trash, without suffering from sorting.

The city authorities will have no problems with creating a sector that no one needs, purchasing expensive equipment, separate accumulation, processing, and marketing. Just leave these processes to specialized businesses that can take over the collection, sorting and delivery of everything else to the tower.
The big problem is to clean up all areas of cities from the existing, so-called unauthorized landfills.

There is a unique opportunity to completely combine all landfills and fresh waste into a single structure. Use rotting as a useful generator of heat, and many chemical elements, exclude environmental pollution and create unique opportunities for the emergence of a new terrain - create ski slopes in winter, new areas for growing any crops, green areas in summer and free up significant areas from landfills to restore natural fields, meadows, forests. On the top of an artificial mountain, you can arrange viewing platforms, recreation areas, museums, such as in Irkutsk, https://www. irk.ru/news/articles/20160718/museum/, a museum of rubbish is arranged, figure 2. You can also do this here. On the slope and inside in a specially prepared room.

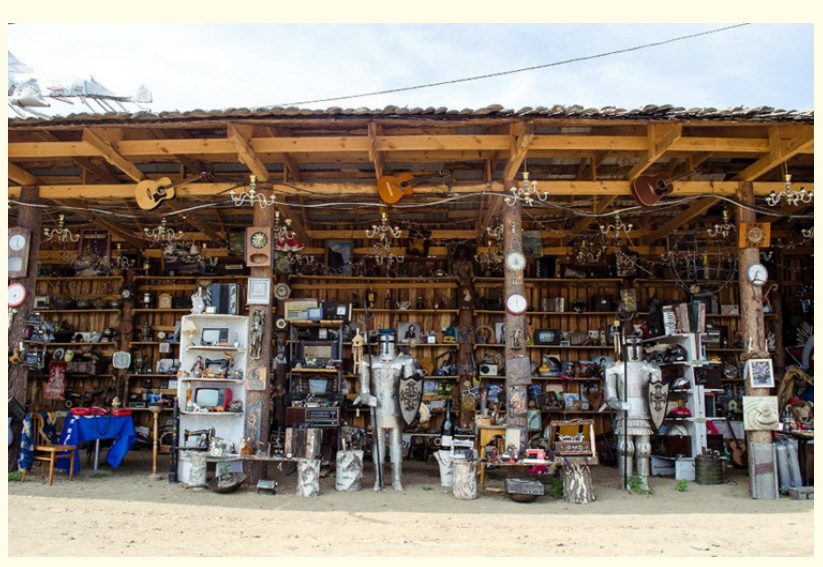

Figure 2

On the slopes you can arrange ski slopes with lifts.

The resulting effect should be a real reduction in the anthropogenic impact on the climate.

I invite you to cooperation.

Volume 4 Issue 6 June 2021

C) All rights are reserved by Khalidullin $0 H$. 